\title{
Resenha
}

\section{O grande valor de um dicionário sobre Ética Global}

\author{
Review \\ The great value of a dictionary on Global Ethics \\ Reseña \\ El gran valor de un diccionario de Ética Global
}

Sandra Mara Campos Alves ${ }^{1}$

\section{Resumo}

Trata-se de resenha da obra intitulada Dictionary of Global Bioethics que se destina a apresentar termos, conceitos e teorias relacionas à bioética global. Reúne mais de 500 verbetes, divididos em quatro categorias distintas: i) organizations; ii) documents; iii) persons; e iv) topics. É uma obra voltada não apenas para estudantes, mas para todos os profissionais que desejam conhecer e compreender os verbetes mais relevantes utilizados no campo da bioética global, constituindo-se em importante ferramenta de promoção e introdução ao tema.

\section{Palavras-chave}

Bioética Global. Dicionário. Direitos Humanos.

\section{Abstract}

It is a review of a work entitled Dictionary of Global Bioethics that is intended to present terms, concepts and theories related to global bioethics. It gathers more than 500 entries, divided into four distinct categories: i) organizations; ii) documents; iii) persons; and iv) topics. It is a work aimed not only for students, but for all professionals who wish to know and understand the most relevant terms used in the field of global bioethics, constituting a valuable tool for promoting and introducing the subject.

\section{Keywords}

Global Bioethics. Dictionary. Human Rights.

\section{Resumen}

Es una revisión de un trabajo titulado Dictionary of Global Bioethics que pretende presentar términos, conceptos y teorías relacionados con la bioética global. Reúne más de 500 inscripciones, divididas en cuatro categorías distintas: i) organizations; ii) documents; iii) persons y iv) topics. Es un trabajo dirigido no solo a los estudiantes, sino a todos los profesionales que deseen conocer y comprender los términos más relevantes utilizados en el campo de la bioética global, constituyéndose en una importante herramienta para promover e introducir el tema.

\section{Palabras clave}

Bioética Global. Diccionario. Derechos Humanos.

\footnotetext{
${ }^{1}$ Doutora em Saúde Coletiva, Universidade de Brasília, Brasília, Brasil; pesquisadora em Saúde Pública, coordenadora, Programa de Direito Sanitário, Fundação Oswaldo Cruz, Brasília, Brasil. https://orcid.org/0000-0001-6171-4558. E-mail: smcalves@gmail.com
} 
Elaborar um dicionário que exige a identificação e compilação de verbetes diversos seguidos de informações e/ou referências sobre o tema é tarefa hercúlea e, no campo da Bioética Global, tal empreitada se reveste de relevante magnitude, tendo em vista a necessidade de abordagem de termos, conceitos e teorias diversas relacionados ao tema. É o primeiro dicionário no domínio da Bioética Global que, na esteira do pioneiro da bioética Van Rensselaer Potter, extravasa as questões especificamente médicas e individuais ou exclusivamente humanas e engloba também preocupações éticas com a vida em geral, incluindo vida animal, preservação ambiental e equilíbrio ecossistêmico. A Bioética Global hoje, ao ir além da perspectiva anglo-saxônica originária, abarca os contributos que diferentes espaços geoculturais têm dado à bioética, nomeadamente o brasileiro.

Esse foi o desafio enfrentado pelos professores Henk ten Have e Maria do Céu Patrão Neves ao organizarem e redigirem em parceria o Dictionary of Global Bioethics (1), publicado em 2021 pela Springer e que reúne mais de 500 verbetes, divididos em 4 categorias distintas: i) organizations; ii) documents; iii) persons e iv) topics.

A ampla experiência dos especialistas autores da obra garantiu a qualidade final do trabalho que se constitui em importante ferramenta de consulta a todos aqueles que querem conhecer e compreender termos relacionados ao campo emergente da Bioética Global. O professor Henk ten Have tem passagem em instituições acadêmicas como a University of Limburg (Maastricht) e University Medical Center Nijmegen, ambas na Holanda, e atualmente é professor emérito da Duquesne University, nos Estados Unidos da América. É também autor de várias publicações sobre bioética além de ter atuado como coordenador do Comitê Internacional de Bioética da UNESCO. A professora Maria do Céu Patrão Neves, por sua vez, é professora titular de Ética na Universidade dos Açores, além de atuar como professora regular de cursos de mestrado e doutorado em Bioética, em diversas universidades. Adiciona-se ainda ao seu currículo uma ampla experiência como consultora em ética para o Presidente da República português e instituições internacionais, entre elas a Comissão Europeia.

Segundo os próprios autores declaram no prefácio, a obra tem como objetivo "to assist those who want to understand the most commonly used concepts in this emerging field of global bioethics" (1). E nessa mesma perspectiva os autores advertem:

The presentations are succinct much as is the case with regular dictionaries and aim to help the reader to get an initial feel for meaning, content, relevance, and associated issues. Although it does not always provide final definitions (which is sometimes difficult because the field is emerging and developing) the topics do provide dynamic 
conceptualizations and thematic problematizations that elucidate what is at stake and spell out the various perspectives and related challenges as briefly as possible (1).

No momento atual em que o mundo passa por uma crise sanitária com repercussões econômicas e sociais que perdurarão para além da pandemia, o Dictionary of Global Bioethics configura-se em importante ferramenta de promoção do tema, capaz de induzir e instigar discussões sobre o futuro que queremos para o mundo e aqueles que o habitam a partir da apresentação dos termos mais usados na Bioética Global.

A globalização hoje não mais se resume à interdependência política e econômica entre os Estados, alcançando a completa interrelação em torno das questões humanas, com todas as suas inequidades e idiossincrasias (2). Nesse contexto, destaca-se a necessária proteção aos direitos humanos, à dignidade humana e às liberdades individuais, consideradas como marcos norteadores dessa jornada.

Como bem advertiu Bobbio (3) ao destacar os avanços no processo de reconhecimento de direitos humanos, os obstáculos atuais não residem propriamente na enunciação desses direitos, mas na sua efetivação, vez que condicionada ao desenvolvimento global da própria civilização. Barreiras procedimentais e substantivas à efetivação dos direitos humanos são constantemente verificadas, apesar de avanços nos estatutos jurídicos nacionais e internacionais voltados ao seu reconhecimento e proteção.

Essa perspectiva também se aplica à saúde que, apesar de historicamente ter sido objeto de interesse e estudo, apenas com o advento do Estado Moderno teve sua condição de direito humano e social alcançada. Somente a partir desse novo paradigma que coube ao Estado o papel de guardião e realizador de ações e serviços voltados a sua efetivação.

Desde então, a busca pelo mais alto padrão de saúde, reconhecida a sua interdependência com os determinantes sociais, passou a ser objetivo central dos governos, estando seu padrão diretamente relacionado ao desenvolvimento social dos países. Contudo, ainda estamos longe de alcançar uma equidade global, e a pandemia de COVID19 retratou bem a diferença abissal que se estende entre os hemisférios Norte e Sul.

As transformações geradas pela tríade da ciência-saúde-tecnologia, atuando à luz de valores éticos, deveriam ser capazes de reduzir essas inequidades, mas para isso a humanidade necessita ainda de uma longa jornada. E, em tempos incertos, a discussão capitaneada pela Bioética Global tem muito a contribuir nesse processo de revisão de princípios e marcos orientadores sendo a presente obra um elemento capaz de democratizar e promover o tema. 
Assim é que o Dictionary of Global Bioethics torna-se fonte de consulta obrigatória para todos aqueles que defendem uma justiça global, com base nos preceitos da igualdade, solidariedade e humanismo.

\section{Referências}

1. Ten Have H, Patrão Neves M. Dictionary of Global Bioethics. Cham, Switzerland: Springer; 2021.

2. Held D, McGrew A. Prós e contras da globalização. Rio de Janeiro: Jorge Zahar Ed.; 2001.

3. Bobbio N. A era dos direitos. Rio de Janeiro: Elsevier; 2004.

Alves SMC. O grande valor de um dicionário sobre Ética Global. Cadernos Ibero-Americanos de Direito Sanitário. 2021 jul./set.;10(3):231-234.

https://doi.org/10.17566/ciads.v10i3.835 